\title{
Plasma Cell Neoplasms
}


Michael A. Linden • Robert W. McKenna Editors

\section{Plasma Cell Neoplasms}

A Morphologic, Cytogenetic and Immunophenotypic Approach

照 Springer 


\section{Editors}

Michael A. Linden

Department of Laboratory Medicine and Pathology

University of Minnesota

Minneapolis

MN

USA
Robert W. McKenna

Department of Laboratory Medicine and Pathology

University of Minnesota

Minneapolis

MN

USA

ISBN 978-3-319-10917-6

ISBN 978-3-319-10918-3 (eBook)

DOI 10.1007/978-3-319-10918-3

Library of Congress Control Number: 2014955544

Springer Cham Heidelberg New York Dordrecht London

(C) Springer International Publishing Switzerland 2016

This work is subject to copyright. All rights are reserved by the Publisher, whether the whole or part of the material is concerned, specifically the rights of translation, reprinting, reuse of illustrations, recitation, broadcasting, reproduction on microfilms or in any other physical way, and transmission or information storage and retrieval, electronic adaptation, computer software, or by similar or dissimilar methodology now known or hereafter developed.

The use of general descriptive names, registered names, trademarks, service marks, etc. in this publication does not imply, even in the absence of a specific statement, that such names are exempt from the relevant protective laws and regulations and therefore free for general use.

The publisher, the authors and the editors are safe to assume that the advice and information in this book are believed to be true and accurate at the date of publication. Neither the publisher nor the authors or the editors give a warranty, express or implied, with respect to the material contained herein or for any errors or omissions that may have been made.

Printed on acid-free paper

Springer International Publishing AG Switzerland is part of Springer Science+Business Media (www.springer.com). 


\section{Preface}

Plasma cell neoplasms, including plasma cell myeloma, did not start to appear in the medical literature until the 1840s [1]. In 1847, Dr. Henry Bence Jones described the features of a urine precipitate in a patient that likely had plasma cell myeloma [1]. Nearly 100 years later the field was revolutionized by the invention of immunoelectrophoresis (1953) and immunofixation (1964) [1]. These tools improved the way in which plasma cell neoplasms are diagnosed and monitored. In the last 20 years, there have been remarkable changes in the treatment approach to myeloma patients, including bone marrow transplantation and innovative chemotherapy (immunomodulatory drugs and proteasome inhibitors), that have increased the median survival of standard risk patients to greater than 10 years [2].

This book is primarily intending for a pathology audience, including trainees and practicing pathologists. While these neoplasms may comprise a minority cases in our practices, improved patient outcomes means that we are continuously seeing a greater proportion of bone marrow biopsies from patients with a diagnosis of plasma cell neoplasm. Moreover, as new ancillary diagnostic testing is continuously introduced to our practice, it is important for us to be familiar with the right tools to make an accurate diagnosis and to guide our clinician allies on test utilization.

There are multiple pieces of data necessary to render a diagnosis of plasma cell neoplasm and to provide important prognostic and predictive information. These data include clinical findings, laboratory data, morphologic features, immunophenotype, and cytogenetics. The first two chapters of this book approach how we detect and enumerate paraproteins, by electrophoretic and/or immunoturbidimetric/ nephelometric methods. Next, we review how a careful bone marrow examination is a key component of the diagnosis, often with the aid of immunohistochemical stains. Building on the first three chapters, we next look at the current 2008 WHO classification of plasma cell neoplasms, including monoclonal gammopathy of undetermined significance, solitary plasmacytoma, primary amyloidosis, and plasma cell myeloma [3]. Chapters 5 and 6 provide an overview of cytogenetic and flow cytometric features of plasma cell neoplasms, and their role in diagnosis and prognosis. The final two chapters may be the most important-while this book is primarily intended for pathology trainees and practicing pathologists, it's important to recognize that patients and clinicians depend on our timely, high quality diagnoses 
to guide care. Chapter 7 will give a perspective on how a clinician would approach the treatment of a patient with a plasma cell neoplasm, and Chapter 8 will provide guidelines for how pathologists can most effectively summarize and communicate their findings in a diagnostic report.

1. Kyle RA. Multiple myeloma: an odyssey of discovery. Br J Haematol. 2000;111(4):1035-44.

2. Rajkumar SV, Gahrton G, Bergsagel PL. Approach to the treatment of multiple myeloma: a clash of philosophies. Blood. 2011;118(12):3205-11.

3. Swerdlow SH, Campo E, Harris NL, Jaffe ES, Pileri SA, Stein H, et al. WHO classification of tumours of hematopoietic and lymphoid tissues. 4th edn. Lyon: International Agency for Research on Cancer; 2008.

Michael A. Linden, MD, PhD

Robert W. McKenna, MD 


\section{Contents}

Clinical Protein and Immunofixation Electrophoresis

Jonathan R. Genzen

Serum Free Light Chain Analysis

25

Rajeevan Selvaratnam, Jing Cao and Amy B. Karger

Plasma Cell Neoplasms: Morphology and Immunohistochemistry

Garth Aasen and Robert W. McKenna

Classification of Plasma Cell Neoplasms

Sophia L. Yohe

Conventional and Molecular Cytogenetics in Plasma Cell Neoplasms.

Michelle Dolan

Role of Flow Cytometry in Plasma Cell Neoplasms

Beenu Thakral, Kristy Wolniak and Michael A. Linden

Plasma Cell Neoplasms, A Therapeutic Approach

Brian L. McClune and Sagar S. Patel

Standardized Synoptic Reports for Plasma Cell Neoplasms:

Integration of Laboratory and Clinical Data

Elizabeth L. Courville, Zohar Sachs and Michael A. Linden

Index 


\section{Contributors}

Garth Aasen Department of Pathology, Borgess Medical Center, Kalamazoo, MI, USA

Jing Cao Department of Laboratory Medicine and Pathology, University of Minnesota, Minneapolis, MN, USA

Elizabeth L. Courville Division of Hematopathology, Department of Laboratory Medicine and Pathology, University of Minnesota, Minneapolis, MN, USA

Michelle Dolan Department of Laboratory Medicine and Pathology, University of Minnesota Medical School, Minneapolis, MN, USA

Jonathan R. Genzen Department of Pathology, University of Utah School of Medicine/ARUP Laboratories, Salt Lake City, UT, USA

Amy B. Karger Department of Laboratory Medicine and Pathology, University of Minnesota, Minneapolis, MN, USA

Michael A. Linden Division of Hematopathology, Department of Laboratory Medicine and Pathology, University of Minnesota, Minneapolis, MN, USA

Brian L. McClune Department of Medicine, Division of Hematology, Oncology, and Transplantation, University of Minnesota Medical Center, Minneapolis, MN, USA

Robert W. McKenna Department of Laboratory Medicine and Pathology, University of Minnesota, Minneapolis, MN, USA

Sagar S. Patel Department of Medicine, University of Minnesota Medical Center, Medicine Education Office, Minneapolis, MN, USA

Zohar Sachs Division of Hematology, Oncology, and Transplantation, Department of Medicine, Medical School, University of Minnesota, Minneapolis, MN, USA

Rajeevan Selvaratnam Department of Laboratory Medicine and Pathology, University of Minnesota, Minneapolis, MN, USA 
Beenu Thakral Department of Laboratory Medicine and Pathology, University of Minnesota, Minneapolis, MN, USA

Kristy Wolniak Department of Pathology, Northwestern University Feinberg School of Medicine, Chicago, IL, USA

Sophia L. Yohe Division of Hematopathology, Department of Laboratory Medicine and Pathology, University of Minnesota, Minneapolis, MN, USA 